\title{
Entraves encontrados na prática do planejamento de aulas da Educação Física
}

\section{escolar}

Obstacles encountered in the practice of planning classes in school Physical Education

Obstáculos encontrados en la práctica de la planificación de las clases de Educación Física en la escuela

\section{Resumo}

$\mathrm{O}$ presente artigo trata-se de uma pesquisa bibliográfica que objetivou refletir sobre os entraves encontrados no planejamento de aulas da Educação Física escolar. Em consonância com o referencial teórico, foi possível tecer algumas considerações sobre o tema. Nesse sentido, observarmos que, além da falta de materiais e infraestrutura adequada, a escassez de estudos que tratam sobre a organização de conteúdos e o planejamento de aulas na educação física apresentam-se como um dos principais obstáculos para a prática pedagógica dos professores. Dessa forma, as abordagens pedagógicas críticas e os documentos norteadores aparecem como propostas importantes para a organização do trabalho docente. Assim, é necessário haver um maior debate em torno de estudos que possam subsidiar a prática pedagógica, propondo discussões que contemplem formas de organizar e planejar os conteúdos das aulas de maneira sistematizada e aprofundada. Acreditamos que a discussão sobre essa temática é importante para que o professor de Educação Física possa embasar a sua prática em conhecimentos teóricos e, consequentemente, organizar o trabalho pedagógico de forma crítica e reflexiva.

Palavras-chave: Educação física; Planejamento de aulas; Ensino.

\begin{abstract}
The present article is a bibliographical research that aimed to reflect on the obstacles found in the planning of classes in school Physical Education. In line with the theoretical framework, it was possible to make some considerations on the subject. In this sense, we observe that, in addition to the lack of materials and adequate infrastructure, the scarcity of studies dealing with the organization of content and the planning of classes in physical education are presented as one of the main obstacles to the pedagogical practice of teachers. In this way, critical pedagogical approaches and guiding documents appear as important proposals for the organization of teaching work. Thus, it is necessary to have a greater debate around studies that can subsidize the pedagogical practice, proposing discussions that contemplate ways to organize and plan the contents of the classes in a systematic and in-depth way. We believe that the discussion on this theme is important so that the Physical Education teacher can base their practice on theoretical knowledge and, consequently, organize the pedagogical work in a critical and reflective way.
\end{abstract}

Keywords: Physical education; Lesson planning; Teaching.

\section{Resumen}

Este artículo es una investigación bibliográfica que tuvo como objetivo reflexionar sobre los obstáculos encontrados en la planificación de las clases de Educación Física en la escuela. De acuerdo con el marco teórico, fue posible hacer algunas consideraciones sobre el tema. En este sentido, observamos que, además de la falta de materiales e infraestructura adecuados, la escasez de estudios sobre la organización de los contenidos y la planificación de las clases en educación física son uno de los principales obstáculos para la práctica pedagógica de los profesores. Así, los enfoques pedagógicos críticos y los documentos guía aparecen como propuestas importantes para la organización del trabajo docente. Por lo tanto, es necesario tener un mayor debate en torno a los estudios que pueden apoyar la práctica pedagógica, proponiendo discusiones que contemplen formas de organizar y planificar los contenidos de las clases de manera sistematizada y profunda. Creemos que la discusión sobre este tema es importante para que el profesor de educación física pueda basar su práctica en el conocimiento teórico y, consecuentemente, organizar el trabajo pedagógico de manera crítica y reflexiva.

Palabras clave: Educación física; Planificación de clases; Enseñanza. 


\section{Introdução}

A Educação Física (EF) é um componente curricular obrigatório da educação básica, que trata, "pedagogicamente, na escola, do conhecimento de uma área denominada cultura corporal" (Soares et al., 2012). Essa área é configurada por meio de conhecimentos corporais construídos historicamente, como a dança, a ginástica, a luta, jogos, brincadeiras e esportes. Por estar inserida na matriz curricular da escola e apresentar conhecimentos específicos, a Educação Física passa a cumprir as exigências da instituição escolar, dentre elas, as ações que envolvem o planejamento e organização dos conteúdos das aulas (Jahn, 2004).

Para analisarmos sobre o planejamento na Educação Física escolar, primeiramente é importante definir o que é planejamento. Dentre os estudiosos desse campo, destacamos o significado de planejamento abordado por Vasconcellos (2000), Gandin e Cruz (2006) e Libâneo (2013), apontando também algumas considerações e reflexões que os autores trazem acerca da importância do ato de planejar.

Vasconcellos (2000) define o planejamento como uma ferramenta capaz de intervir na realidade, ou seja, apresenta-se como instrumento de reflexão e transformação. Para complementar esse posicionamento, Libâneo (2013, p.246) destaca que o planejamento se trata de "um processo de racionalização, organização e coordenação da ação docente, articulando a atividade escolar e a problemática do contexto social". Nessa perspectiva, o autor aponta que o planejamento escolar é influenciado constantemente por questões econômicas, políticas e culturais, e por sofrer essas interferências, torna-se importante que o professor defina qual projeto-político pedagógico pretende desenvolver, pois, se essas questões não estiverem claras, corre-se o risco de o trabalho docente ser ditado pelos interesses dominantes da sociedade.

$\mathrm{Na}$ visão do referido autor, o ato de planejar no contexto escolar apresenta-se como ferramenta que envolve convicções relacionadas ao modelo de sociedade que almejamos, ou seja, estabelece qual rumo queremos para o processo educativo (Libâneo, 2013). Corroborando com essa ideia, Soares et al. (2012) destacam que o professor deve ter bem claro quais os valores, a ética e a moral que acredita que são importantes de estabelecer através de sua prática pedagógica.

Nessa perspectiva, o planejamento apresenta intencionalidade pedagógica que constitui peça fundamental para o processo de construção do indivíduo, sendo importante que o professor entenda essa atividade como uma prática pedagógica significativa, consciente e reflexiva.

Menegolla e Sant'Anna (2002) explicam que o planejamento se apresenta como instrumento importante para o professor nortear o processo de ensino-aprendizagem e prever ações que possam sanar possíveis deficiências apresentadas pelos alunos. Vasconcellos (2000) corrobora com os apontamentos supracitados e afirma que o planejamento ajuda a antecipar ações para atingir resultados desejados, servindo de parâmetro para o professor analisar as dificuldades que ainda precisam ser superadas e, assim, possa ser capaz de intervir em uma situação real e transformá-la.

$\mathrm{O}$ ato de planejar envolve um processo que engloba toda a escola, ou seja, todos os atores que fazem parte do processo de ensino-aprendizagem (Menegolla \& Sant'anna, 2002). Nesse sentido, a EF como componente curricular obrigatório, que apresenta conhecimentos específicos e que devem ser organizados e sistematizados, não está excluída do processo de planejamento.

Compreendemos que a Educação Física escolar, assim como as outras disciplinas, exige organização para direcionar a ação pedagógica e orientar os conhecimentos que serão transmitidos aos alunos. Nesse sentido, é necessário que o fazer pedagógico seja embasado em conhecimentos científicos que possam legitimar o trabalho docente na escola (Barni \& Schneider, 2003).

Assim, partindo da importância do planejamento para a prática docente e para o processo de ensino aprendizagem, este estudo objetiva investigar os entraves encontrados na prática do planejamento de aulas da Educação Física Escolar. Para a investigação, foi realizada uma pesquisa bibliográfica com levantamento de estudos e pesquisas que puderam subsidiar as discussões e reflexões sobre essa temática. 


\section{Metodologia}

Para que uma investigação atinja os objetivos propostos, é necessária a escolha de uma abordagem metodológica adequada, para compreender o fenômeno a ser estudado. Nesse sentido, no presente estudo optamos pela pesquisa qualitativa, pois o objeto de estudo não consiste em quantificar valores e sim aprofundar no estudo de um fenômeno, analisando o problema processualmente (Ludke \& André, 1986).

O delineamento metodológico está pautado na pesquisa bibliográfica, que, de acordo com Gil (2002, p. 44-45) “[...] é desenvolvida com base em material já elaborado, constituído principalmente de livros e artigos científicos. A principal vantagem da pesquisa bibliográfica é possibilitar que o investigador obtenha um grande número de informações sobre a temática, por isso é necessário [...] analisar em profundidade cada informação para descobrir possíveis incoerências ou contradições e utilizar fontes diversas, cotejando-as cuidadosamente."

Nesse enfoque buscamos, por meio de uma pesquisa qualitativa de cunho bibliográfico, o caminho que norteou nossas reflexões frente nosso objeto de estudo, tornando possível uma melhor compreensão dos fundamentos sobre a temática.

\section{Resultados e Discussão}

A prática do planejamento na EF escolar é influenciada por diversos fatores, dentre eles, podemos apontar a falta de materiais, infraestrutura precária das escolas e a escassez de estudos que abordam sobre a temática do planejamento e da organização dos conteúdos na EF escolar.

Segundo Faria Filho e Vago (2001), a falta de materiais e estrutura física adequada é um dos fatores que podem interferir e modificar o planejamento e a execução das atividades propostas pelo professor, comprometendo a prática pedagógica e a concretização dos planos de trabalho. No entanto, o debate em torno do espaço físico da escola é um assunto delicado, pois o fato de alguns professores associarem a EF somente ao esporte concretiza-se como maior empecilho para o desenvolvimento dos conteúdos na escola (Betti, 1999). De acordo com Betti (1999), o professor sempre idealiza as aulas na quadra, assim, quando a escola não dispõe de uma infraestrutura adequada para a realização da prática da EF, as aulas acabam sendo prejudicadas.

É inegável que a inexistência de materiais e de espaços adequados interfere de modo significativo no trabalho pedagógico, no entanto as dificuldades encontradas no contexto escolar não devem impossibilitar o professor de oferecer um melhor conteúdo e de proporcionar aos alunos o conhecimento e a vivência da cultura corporal (Betti,1999).

Para Damazio e Silva (2008), a ausência e a pouca qualidade de espaço físico para o ensino da EF estão relacionadas à desvalorização social dessa disciplina e à falta de investimentos do governo com a educação pública. E, devido a esses entraves, é importante que o docente busque "mecanismos de intervenção, tanto no cotidiano, como em processos de discussões mais amplos no campo político e social", de forma a participar ativamente da organização da escola, contribuindo para que novas práticas escolares sejam consolidadas (Damazio \& Silva, 2008, p.195).

Além dos entraves apontados por Faria Filho e Vago (2001) e Betti (1999), Bossle (2002) afirma que o ato de planejar a aula de $\mathrm{EF}$, e, consequentemente o planejamento de ensino, não tem sido um assunto de grande debate e reflexões para os estudiosos, haja vista que poucas são as publicações científicas que abordam essa temática na EF escolar. De acordo com Lopes et al. (2016), a falta de aprofundamento de produções nessa área pode contribuir para reforçar o caráter de improvisação nas aulas de educação física, secundarizando a importância do planejamento na orientação do trabalho docente.

A escassez de estudos que norteia a prática dos professores de EF aparece como obstáculo para que os diversos conteúdos da cultura corporal de movimento sejam abordados de forma aprofundada (Rosário \& Darido, 2005), nesse sentido, os autores em pauta destacam que: 
Alguns professores de Educação Física têm sistematizado, aprofundado e diversificado os conteúdos conforme suas próprias experiências, erros, acertos, etc., pois grande parte da produção teórica da Educação Física ainda não possibilitou a construção de princípios que pudessem nortear tal prática (Rosário \& Darido, 2005, p.168).

Impolcetto et al. (2007) acrescentam que a falta de elementos práticos e teóricos sobre conteúdos considerados pouco relevantes contribui para que muitos temas não sejam discutidos, já que alguns docentes apresentam dificuldade em planejar e transmitir esses conteúdos na escola, priorizando temáticas que sentem mais segurança e que apresentam maior aceitação pelos alunos. Nessa perspectiva, os autores consideram importante a discussão em torno de estudos que forneçam suporte para construção e desenvolvimento da prática pedagógica, destacando que esses trabalhos sejam apenas um meio de orientação para o trabalho docente e não algo engessado que não possa sofrer adequações (Impolcetto et al., 2007).

Além dos poucos estudos que possam contribuir com a construção do planejamento, Freire e Scaglia (2003) e Oliveira (2004) apontam que o fato da EF não possuir conteúdos sistematizados, ou seja, critérios definidos de como os conteúdos são organizados ao longo das séries escolares, também se apresenta como entrave e questionamento em torno da organização dos conteúdos no planejamento.

Vago (1999) afirma que a Lei de Diretrizes e Bases da Educação Nacional (1996) não definiu critérios para a organização do ensino, o que contribuiu para que a EF fosse inserida no âmbito escolar de diversas maneiras, restringindo muitas vezes o seu papel em cumprir apenas o mínimo previsto em lei

Sobre a organização e sistematização dos conteúdos, Rosário e Darido $(2005$, p.168) criticam o fato de que "grande parte da produção teórica da Educação Física ainda não possibilitou a construção de princípios que pudessem nortear tal prática" e por isso muitos professores planejam as aulas conforme suas experiências.

A carência na produção acadêmico-científico na Educação Física se torna abundante quando o foco é o ensino médio, "deixando os professores desse ciclo de escolarização com dificuldades de encontrar um rumo para o desenvolvimento desse componente curricular", o que aponta para a necessidade de ampliação de pesquisas produzidas que possam subsidiar a construção de didáticas específicas para a etapa final da educação básica (Moreira, Simões \& Martins, 2010, p.355 como citado em Rufino et al., 2014).

Para Kunz (2004), pensar em um programa mínimo de conteúdos seria uma forma de definir os objetivos de cada série ou ciclo, de forma a resolver a "bagunça" que se estabeleceu nessa disciplina. Em oposição aos pensamentos expostos por Kunz (2004), Daólio (2002) discorda da construção de um currículo inflexível e engessado para todas as escolas, e reforça a necessidade de considerar os aspectos culturais e o contexto escolar na organização do planejamento.

No entanto, Daólio (2002) acredita que as propostas curriculares podem ser utilizadas como eixo norteador da prática pedagógica e não como algo exato e acabado, devendo ser construídas e debatidas com o corpo discente. Neira e Nunes (2006) também reforçam a importância de considerar as experiências dos alunos na seleção dos conteúdos, considerando sempre as especificidades de cada local e o projeto pedagógico da escola.

A partir dos anos 1980, iniciam os estudos e pesquisas que passam a discutir a importância de fundamentar a Educação Física como componente curricular que apresenta conteúdos específicos a serem ensinados no âmbito escolar. Nesse movimento, surgem as abordagens pedagógicas da Educação Física que são definidas como "movimentos engajados na renovação teórico-prático com o objetivo de estruturação do campo de conhecimentos que são específicos da Educação Física" (Azevedo \& Shigunov, 2000, p.1).

Segundo Darido (2003) os professores apoiam-se nas abordagens pedagógicas para planejar e selecionar os conteúdos nas aulas. Essas considerações remetem ao princípio de que o trabalho docente sofre influências das concepções didáticopedagógicas existentes na área da EF. 
Nesse contexto, dentre as abordagens que trazem contribuições para o planejamento dos professores de EF, destacamos, nesta pesquisa, as seguintes: crítico-emancipatória, defendida por Elenor Kunz; a abordagem crítico-superadora, do Coletivo de Autores; a abordagem plural, proposta por Jocimar Daólio; Saúde renovada, de Guedes e Guedes; e a abordagem da concepção de aulas abertas a experiências, proposta por Hildebrandt.

A abordagem crítico-emancipatória, proposta por Kunz (2004), tem como objetivo promover uma educação emancipadora de caráter crítico e reflexivo, tentando romper com o caráter hegemônico do esporte tecnicista. Nesse sentido, o autor fundamenta-se no desenvolvimento de três competências que contribuem para a emancipação dos sujeitos: a competência objetiva, a competência social e a competência comunicativa.

Segundo Kunz (2004), a competência objetiva refere-se aos conhecimentos específicos de um componente curricular que são transmitidos para o aluno desenvolver a autonomia. Esses conhecimentos devem promover "um ensino de libertação de falsas ilusões, de falsos interesses e desejos, criados e construídos nos alunos pela visão de mundo que apresentam a partir de conhecimentos colocados à disposição pelo contexto sociocultural onde vivem" (Kunz, 2004, p.121). Para que o ensino seja de libertação, o autor afirma que é necessário mudar os objetivos de como o esporte vem sendo abordado na escola, que tem normatizado e padronizado os movimentos como forma de atender a concepção de rendimento imposta pela sociedade industrial. $\mathrm{Na}$ concepção do autor, "torna-se imperativo uma transformação didático pedagógica para torná-lo uma realidade educacional potencializadora de uma educação crítico-emancipatória" (Kunz, 2004, p.126).

A competência social diz respeito à compreensão que o aluno deve adquirir nas experiências de interação social, que deverá contribuir para reflexões em torno de dos diferentes papéis sociais existentes no esporte, problematizando, dessa forma, questões como diferenças e discriminações. Na competência comunicativa, Kunz (2004) alerta sobre a importância de se considerar a linguagem verbal e não apenas o movimento, para que o aluno possa saber se comunicar e interpretar a comunicação dos outros de forma crítica e reflexiva.

Nesse sentido, a emancipação é entendida pelo autor como o processo de desenvolvimento do uso da razão crítica, do agir social, cultural e esportivo desenvolvido pela educação. Essa concepção busca trabalhar o esporte pela transformação didático-pedagógica, que tem como objetivo "superar o interesse técnico do ensino e assumir um interesse críticoemancipatório" (Kunz, 2004, p.138). Segundo o autor supracitado, a metodologia de ensino crítico-emancipatória não se restringe ao conteúdo esporte, mas também considera os demais conhecimentos da cultura do movimento, como a ginástica, dança, jogos, lutas.

Outra abordagem que merece reconhecimento na EF escolar é a crítico-superadora. Essa concepção, defendida por Soares et al. (2012), trata da cultura corporal como conhecimento da EF que se constitui de conteúdos como jogos, ginástica, lutas, esportes, dança e outros.

A cultura corporal é definida como "resultado de conhecimentos socialmente produzidos e historicamente acumulados pela humanidade que necessitam ser retraçados e transmitidos para os alunos na escola" (Soares et al., 2012, p.40). Segundo os autores mencionados, o objetivo do currículo na abordagem-crítico superadora é promover a leitura crítica da realidade social do aluno, de maneira a fornecer conhecimentos necessários que possam modificar a sociedade capitalista.

Para a seleção dos conteúdos, essa abordagem aponta princípios curriculares considerados importantes, como: a relevância social do conteúdo, que considera a realidade social do aluno; a adequação às possibilidades sociocognitivas do aluno; a simultaneidade dos conteúdos, que explica que os conteúdos não podem ser abordados de forma isolada; a espiralidade da incorporação dos conhecimentos das referências do pensamento, que considera a ampliação do conhecimento; e a provisoriedade do conhecimento. 
Nessa proposta pedagógica, a avaliação não se restringe ao aspecto técnico ou a seleção de talentos esportivos, pois esse modelo avaliativo segrega e seleciona os alunos na EF escolar. Para os autores, é necessário que a avaliação envolva as capacidades cognitivas, habilidades, valores sociais e políticos que possam contribuir para o processo de formação crítica.

Outra abordagem pedagógica da EF é a concepção Plural, que é defendida por Daólio (1995). Na abordagem Plural, Daólio (1995) discute a EF numa perspectiva cultural, que considera as individualidades e diferenças dos alunos a partir da discussão de que os corpos não podem ser resumidos a uma visão biológica. O autor levanta a questão de que "se os corpos forem vistos como unicamente biológicos, todos os alunos possuirão o mesmo corpo e as mesmas capacidades; em consequência, uma determinada prática servirá para todos os alunos, sempre" (Daólio, 1995, p.134).

Baseado nessas considerações o autor acrescenta que os corpos se manifestam de formas diferentes, porque representam culturas diferentes. Ao considerar que o corpo é dotado de significações sociais, observa-se a necessidade de que a EF contemple na prática pedagógica os aspectos culturais, garantindo uma participação mais efetiva dos alunos através do respeito à diversidade presente nas manifestações da cultura corporal.

A abordagem da Saúde renovada, discutida por Guedes e Guedes (1996), propõe que a EF enquanto componente curricular tem o papel de discutir temas que abordam a qualidade vida, prática de atividade física, hábito de vida saudável, sedentarismo e obesidade. Os autores supracitados ressaltam que é importante apresentar aos alunos, além de conceitos sobre o aspecto da prática da atividade física, os fundamentos teóricos que justificam a sua relação com a manutenção da saúde.

Guedes (1999) entende que a EF deve assumir uma proposta pedagógica voltada à perspectiva da promoção de saúde, de forma que os professores possam proporcionar experiências que auxiliem os alunos a adotarem hábitos de vida saudável.

A respeito da abordagem de aulas Abertas, defendida por Hildebrant-Stramann (2001), propõe um modelo que considera a participação ativa dos alunos na organização do planejamento e nas decisões da aula. Nessa abordagem, os alunos poderão expressar suas opiniões e experiências de forma a desenvolver competências como autonomia, independência e criatividade nas aulas de EF.

Para o autor, essa proposta tem o objetivo de superar os movimentos padronizados nas aulas de EF, "por isso os temas das aulas devem ser ambíguos e complexos, abertos aos interesses e às experiências que os alunos adquiriram nas suas histórias de vida" (Hildebrant-Stramann, 2001, p.71).

Nessa abordagem, o plano metodológico não é entendido como estrutura rígida, opondo-se ao planejamento em que os alunos realizam experiências somente da maneira preparada pelo professor. Dessa forma, Hildebrant-Stramann (2001, p.80) considera que "é imprescindível o professor possibilitar condições de coparticipação no processo ensino-aprendizagem, para que as experiências possam ser vivenciadas em toda, ou quase toda, plenitude". Com isso, a concepção de aulas abertas trouxe a possibilidade de pensar nas aulas de EF de forma coletiva, promovendo o diálogo entre docente e alunos no processo didáticometodológico (Bossle \& Molina Neto, 2009).

Além das abordagens pedagógicas, existem, como proposição da Lei de Diretrizes e Bases da Educação (1996), documentos e orientações que podem ser consultados pelos professores para organização e planejamento dos conteúdos de suas aulas, como os Parâmetros Curriculares Nacionais (PCN’s) e mais recentemente, a sanção da Lei no 13.415 de 2017, a Base Nacional Comum Curricular- BNCC.

Os PCN's são propostas curriculares organizadas pelo Ministério da Educação que visam garantir a todos os alunos da educação básica o acesso a um conjunto comum de conhecimentos (Brasil, 1998). A função primordial dos PCN's é subsidiar a construção dos currículos nas escolas, servindo como apoio para a elaboração de projetos educativos, dos planejamentos de aulas e de reflexão para a prática pedagógica dos professores (Brasil, 1998).

Em relação aos Parâmetros Curriculares Nacionais - PCN's, Darido (2003) aponta o documento como uma abordagem relevante para o debate em torno da construção pedagógica na EF escolar. De acordo com a autora referenciada, os PCN's 
trazem a proposta de articular o conhecimento nas 3 dimensões: conceitual, procedimental, atitudinal, apontando um caminho para superar a visão mecanicista da EF, em que predominava o aspecto procedimental dissociado dos valores, das atitudes e do conhecimento envolvido por trás do fazer.

Para Gramorelli e Neira (2009), o debate em torno da reorientação curricular trouxe reflexões sobre a prática pedagógica e apontou a urgência de se construir um processo educativo voltado para as aprendizagens. Nesse sentido, os PCN's apresentam a perspectiva da formação humana em sua integralidade, que envolve as dimensões culturais, sociais, políticas e efetivas (Torres \& Xavier, 2015).

Como orientação didático-metodológica, os PCN's (Brasil, 1998) trazem a proposta de organizar os conteúdos em três grandes blocos: Esportes, Jogos, Lutas e Ginástica; Atividades Rítmicas e Expressivas; e Conhecimentos sobre o Corpo, que devem ser aprofundados e sistematizados no decorrer da educação básica. O documento traça objetivos da educação física para cada ciclo do ensino fundamental, e para o ensino médio elenca as competências e habilidades que devem ser desenvolvidas pelos alunos no decorrer da última etapa do ensino.

Para o ensino médio, o documento elege a educação para a saúde como orientação central a ser abordada na última etapa da educação básica (Brasil, 2000). Nesse sentido, propõe que os professores de EF devem promover projetos que estimulem a prática de atividade para promoção de hábitos de vida saudável.

De acordo com o grupo que elaborou os PCNEM, observa-se que o número de adolescentes obesos tem aumentado consideravelmente, por isso, faz-se necessário refletir sobre "a retomada da vertente Aptidão Física e Saúde” (Brasil, 2000, p.35).

O documento também aponta propostas de discutir a prática e o aprendizado de exercícios físicos que abordam temas como a flexibilidade, frequência cardíaca, alongamento. Nesse contexto, considera que o avanço tecnológico trouxe mudanças no hábito dos adolescentes, que pode ocasionar a depressão, ansiedade, problemas respiratórios, musculares, por isso, faz-se necessário que o planejamento da EF envolva atividades que contribuam para a qualidade de vida dos alunos (Brasil, 2000).

A BNCC conceitua-se como um "documento de caráter normativo que define o conjunto orgânico e progressivo de aprendizagens essenciais que todos os alunos devem desenvolver ao longo das etapas e modalidades da Educação Básica" (Brasil, 2018, p.7). Segundo a BNCC, as aprendizagens essenciais visam conduzir o aluno ao desenvolvimento de conhecimentos (conceitos e procedimentos), habilidades (práticas cognitivas e socioemocionais), atitudes e valores para resolver demandas complexas da vida cotidiana, do pleno exercício da cidadania e do mundo do trabalho (Brasil, 2018, p. 8).

Para a Educação Física, o documento elege as práticas corporais como elemento central para configuração dos conhecimentos, organizando-os em blocos de unidades temáticas, como: jogos e brincadeiras, esportes, ginásticas, danças, lutas que deverão ser aprofundados no decorrer da educação básica (Neira \& Souza Júnior, 2016).

Segundo Rufino e S. Neto (2016) a BNCC apresenta para a área da Educação Física os objetivos de aprendizagem para cada ciclo de escolaridade, sugerindo formas de sistematizar e diversificar os conteúdos da Educação Física. Os autores supracitados ainda salientam que:

No caso da Educação Física, por sua história fortemente vinculada ao ensino de apenas alguns conteúdos, essa diversificação e consideração de objetivos de aprendizagens baseados em diversas manifestações corporais pode ser visto como um avanço, desde que devidamente compreendido na prática (Rufino \& S. Neto, 2016, p.55).

Nesse sentido, os autores enfatizam que a BNCC pode servir de base para subsidiar a prática pedagógica dos professores de Educação Física e contribuir para a organização do campo educativo dessa área. No entanto, é necessário compreender como esse documento será implementado nas escolas e seus desdobramentos em relação à formação inicial e continuada dos professores. 
De acordo com Neira e Souza Júnior (2016, p. 201) a BNCC na área da Educação Física "pode inspirar docentes a selecionarem, dentre os objetivos arrolados, aqueles que se coadunam com as intenções educativas da escola, definidas coletivamente e com a participação da comunidade".

Boscatto, Impolcetto e Darido (2016, p.101) afirmam que diante dos diversos entraves que os professores enfrentam no processo de ensino-aprendizagem, faz-se necessário a existência de uma base comum que possa orientá-los na organização da prática pedagógica. Segundo os autores supracitados, existem aprendizagens essenciais que devem fazer parte da BNCC, e que, posteriormente, deverão ser complementadas "por uma parte diversificada no currículo escolar". Essa parte diversificada corresponde às especificidades e características culturais de cada região que devem ser consideradas na construção dos currículos escolares.

Impolcetto e Darido (2011) ampliam essa discussão ao afirmarem que a escassez de elementos que possam subsidiar o currículo na $\mathrm{EF}$ faz com que os docentes sistematizem os conteúdos baseados em suas experiências e nas compartilhadas por outros professores da área, por isso, é importante haver documentos balizadores que orientem a prática pedagógica.

Assim, acreditamos que é necessário um maior número de produções acadêmicas que tratam sobre planejamento e organização dos conteúdos de aulas na Educação Física escolar, pois, para que esse componente curricular alcance seus objetivos de promover uma aprendizagem significativa na formação do aluno, é necessário, primeiramente, que o professor tenha subsídios para fundamentar o trabalho docente em conhecimentos científicos que possam legitimar a prática pedagógica.

\section{Considerações Finais}

O estudo bibliográfico empreendido nesse estudo permitiu levantar algumas reflexões sobre os entraves encontrados no planejamento e organização das aulas na Educação Física escolar.

Nesse cenário, analisamos que além das dificuldades enfrentadas pelos professores de Educação Física quanto à questão de infraestrutura inadequada e a falta de materiais que dificultam o planejamento das aulas, outro ponto relevante em relação à essa temática é discutido por autores como Rufino et al. (2014), Impolcetto e Darido (2011) e Bossle (2002). Os autores mencionados apontam que a escassez de estudos sobre planejamento na educação física escolar e a falta de organização de conteúdos apresentam-se como um dos principais entraves para a prática pedagógica, deixando os professores da área sem muitas orientações sobre como os conteúdos devem ser ensinados e aprofundados no decorrer dos anos escolares.

Diante dessas reflexões, as abordagens pedagógicas e os documentos norteadores como os PCN's e mais recentemente, a BNCC, apresentam-se como elementos balizadores para a prática pedagógica na área de Educação Física, trazendo orientações que podem contribuir para o professor sistematizar e planejar os conteúdos de suas aulas. No entanto, é necessário que os documentos norteadores sejam analisados criticamente e adequados ao contexto social no qual estão inseridos.

O debate em torno das abordagens e documentos norteadores trouxeram reflexões para discutir o campo teórico da Educação Física como um componente curricular, que possui conhecimentos específicos, e que, devem ser articulados com as múltiplas dimensões do ser humano. Essas discussões apontam para a perspectiva de desenvolver os conteúdos para além do fazer, mas, envolvem os conceitos e valores que devem ser ensinados aos alunos, o que contribui para distanciar a Educação Física da visão meramente mecanicista.

Percebemos que a exígua produção acadêmica sobre o planejamento das atividades pedagógicas na Educação Física escolar demonstra uma desvalorização da área, principalmente na etapa do ensino médio. A escassez de estudos e orientações para a organização e planejamento dos conteúdos, reflete no trabalho docente dos professores, uma vez que não há um consenso na Educação Física de como os conhecimentos devem ser sistematizados e aprofundados no decorrer das etapas escolares.

Nesse sentido, é necessário um olhar mais atento em relação às produções acadêmicas que possam subsidiar a prática pedagógica dos professores de Educação Física, pois, entendemos que, para que esse componente curricular contribua na 
formação significativa dos alunos, é necessário que os professores disponham de embasamento teórico para transmitir os conhecimentos que serão ensinados.

Assim, esse levantamento bibliográfico evidencia a necessidade de maiores pesquisas que possam corroborar com a prática pedagógica e com a construção de um planejamento crítico e reflexivo na área da Educação Física escolar, dessa forma, recomendamos este trabalho para aqueles que desejam debruçar-se sobre as lacunas e entraves encontrados quando se propõe a planejar ações no âmbito da EF, no sentido de transmutá-la para além de concepções castradoras e inertes.

\section{Referências}

Azevedo, S. E., \& Shigunov, V. (2000). Reflexões sobre as abordagens pedagógicas de Educação Física. Universidade Federal de Santa Catarina. http://kinein.sites.ufsc.br/edit01/artigo2.pdf

Barni, M. J., \& Schneider, E. J. (2003). A educação física no ensino médio: relevante ou irrelevante?. Revista Leonardo Pós, Blumenau, 1 (3), p. 15-20.

Betti, I. C. R. (1999). Esporte na escola: mas é só isso, professor?. Motriz, 1 (1), 25-31. http://files.cursoeducacaofisica.webnode.com/20000008860238611e0/ESPORTE\%20NA\%20ESCOLA\%20-\%20IRENE\%20RANGEL.pdf

Boscatto, J. D., Impolcetto, F. M., \& Darido, S. C. (2016). A Base Nacional Comum Curricular: uma proposição necessária para a Educação Física?. Motrivivência, 28 (48), 96-112. https://periodicos.ufsc.br/index.php/motrivivencia/article/view/2175-8042.2016v28n48p96

Bossle, F. (2002). Planejamento de ensino na educação física - uma contribuição ao coletivo docente. Movimento, 8 (1), 31-39. https://seer.ufrgs.br/Movimento/article/view/2635/1261

Bossle, F., \& Molina Neto, V. (2009). Leituras para (Re)Pensar o Trabalho Coletivo dos Professores de Educação Física. Movimento, 15 (3), 89-107. https://seer.ufrgs.br/Movimento/article/view/6877

Brasil. (2017). Lei $n^{\circ} 13.415$, de 16 de fevereiro de 2017. Altera as Leis nos 9.394, de 20 de dezembro de 1996, que estabelece as diretrizes e bases da educação nacional, e 11.494, de 20 de junho 2007, que regulamenta o Fundo de Manutenção e Desenvolvimento da Educação Básica e de Valorização dos Profissionais da Educação, a Consolidação das Leis do Trabalho - CLT, aprovada pelo Decreto-Lei no 5.452, de 1o de maio de 1943, e o Decreto-Lei no 236, de 28 de fevereiro de 1967; revoga a Lei no 11.161, de 5 de agosto de 2005; e institui a Política de Fomento à Implementação de Escolas de Ensino Médio em Tempo Integral. Brasília, DF.

Brasil. Ministério da Educação. (2018). Base Nacional Comum Curricular. Brasília, DF.

Brasil. Ministério da Educação. Secretaria de Ensino Fundamental. (1998). Parâmetros curriculares nacionais: terceiro e quarto ciclos: Educação Física. Brasília, DF.

Brasil. Ministério da Educação. Secretaria de Educação Média e Tecnológica (2000). Parâmetros Curriculares Nacionais (Ensino Médio). Brasília, DF.

Damazio, M. S., \& Silva, M. F. P. (2008). O ensino da educação física e o espaço físico em questão. Pensar a prática, 11 (2), 197-2017. https://www.revistas.ufg.br/fef/article/view/3590/4098

Darido, S. C. (2003). Educação Física na escola - questões e reflexões. Rio de Janeiro: Guanabara Koogan.

Daólio, J. (1995). Da cultura do corpo. Campinas: Papirus.

Daólio, J. (2002). A cultura da/na Educação Física. Tese, Universidade Estadual de Campinas. Campinas, São Paulo, Brasil.

Faria Filho, L. M., \& Vago, T. M. (2001). Entre relógios e tradições: elementos para uma história dos tempos escolares em Minas Gerais. In Vidal, D. G., \& HilsdorF, M. L. (Orgs.). Tópicos em história da educação. São Paulo: Edusp.

Freire, J. B., \& Scaglia, A. J. (2003). Educação Como Prática Corporal. São Paulo: Scipione.

Gandin, D., \& Cruz, C. H. C. (2006). Planejamento na sala de aula. Petrópolis: Vozes.

Gil, A. C. (2002). Como elaborar projetos de pesquisa. (4a. ed.). São Paulo: Atlas.

Gramorelli, L. C., \& Neira M. G. (2009). Dez anos de parâmetros curriculares nacionais: a prática da Educação Física na visão dos seus atores. Movimento, 15 (4), 107-126. https://seer.ufrgs.br/Movimento/article/view/6863

Guedes, D. P. (1999). Educação para a saúde mediante programas de educação física escolar. Motriz, 5 (1), 10-15. http://www.periodicos.rc.biblioteca.unesp.br/index.php/motriz/article/view/6619

Guedes, D. P., \& Guedes, J. E. R. P. (1996). Associação entre variáveis do aspecto morfológico e desempenho motor em crianças e adolescentes. Revista Paulista de Educação Física, 10 (2), 99-112. http://www.revistas.usp.br/rpef/article/view/138523

Hildebrandt-Stramann, R. (2001). Textos pedagógicos sobre o ensino da Educação Física. Ijuí: Ed. UNIJUÍ. http://www.intaead.com.br/ebooks1/livros/ed\%20fisica/22.\%20TEXTOS\%20PEDAG\%D3GICOS.pdf 
Research, Society and Development, v. 10, n. 9, e55210918410, 2021

(CC BY 4.0) | ISSN 2525-3409 | DOI: http://dx.doi.org/10.33448/rsd-v10i9.18410

Impolcetto, F. M., \& Darido, S. C. (2011). Possibilidades para a sistematização do voleibol na Educação Física escolar. Website do Portal de Revistas Eletrônicas da Universidade Católica de Brasília. https://portalrevistas.ucb.br/index.php/RBCM/article/view/2773

Impolcetto, F. M. et al. (2007). Educação física no ensino fundamental e médio: a sistematização dos conteúdos na perspectiva de docentes universitários sistematização dos conteúdos da educação física. Revista Mackenzie de Educação Física e Esporte, $6 \quad$ (1), 89-109. http://editorarevistas.mackenzie.br/index.php/remef/article/view/1285

Jahn, A.B. (2004). O planejamento das aulas de educação física dos professores que atuam em uma escola pública de Santa Maria (RS). Dissertação, Universidade Federal de Santa Maria, Santa Maria, Rio Grande do Sul, Brasil.

Kunz, E. (2004). Transformação Didático-Pedagógica do Esporte. Ijuí: Unijuí.

Lei n. 9394, de 20 de dezembro de 1996. (1996). Estabelece as Diretrizes e Bases da Educação Nacional. Diário Oficial da União, Brasília, DF.

Libâneo, J. C. (2013). Didática. (2a ed.). São Paulo: Cortez.

Lopes, M. R. S. et al. (2016). Prática do planejamento educacional em professores de educação física: construindo uma cultura do planejamento. Journal of Physical Education. http://www.scielo.br/scielo.php?script=sci_arttext\&pid=S2448-24552016000100144\&lng=en\&nrm=iso

Lüdke, M., \& André, M. E. D. A. (1986). Pesquisa em educação: abordagens qualitativas. São Paulo: EPU.

Menegolla, M., \& Sant'anna, I. M. (2002). Por que planejar? Como planejar?. Rio de Janeiro: Vozes.

Neira, M.G., \& Nunes, M.L.F. (2006). Pedagogia da cultura corporal-Crítica e alternativas. São Paulo: Phorte..

Neira, M. G., \& Souza Júnior, M. (2016). A Educação Física na BNCC: procedimentos, concepções e efeitos. Motrivivência, Florianópolis, 28 (28), p. 188-206.

Oliveira, A. A. B. (2004). Planejando a Educação Física Escolar. In VIEIRA, J. L. L. (Org). Educação Física e Esportes: estudos e proposições. Maringá: EDUEM.

Rosário, L. F. R., \& Darido, S. C. (2005). A sistematização dos conteúdos da educação física na escola: a perspectiva dos professores experientes. Motriz, 11 (3), 167-178. https://www.rc.unesp.br/ib/efisica/motriz/11n3/10LRF.pdf

Rufino, L. G. B. et al. (2014). Educação física escolar no ensino médio: analisando o estado da arte. Revista Brasileira de Ciências do Esporte, 36 (2), 5353 5369. http://revista.cbce.org.br/index.php/RBCE/article/view/2138

Rufino, L. G. B., \& S. Neto S. (2016). Saberes docentes e formação de professores de Educação Física: análise da Base Nacional Comum Curricular (BNCC) na perspectiva da profissionalização do ensino. Motrivivência, 28 (48), 42-60. https://periodicos.ufsc.br/index.php/motrivivencia/article/view/21758042.2016v28n48p42

Soares, C. L et al. (2012). Metodologia do Ensino da Educação Física (Coletivo de Autores). São Paulo: Cortez.

Torres, J. C., \& Xavier, K. (2015). Parâmetros curriculares nacionais: novo paradigma para a formação do professor e da prática docente em educação física? EccoS - Revista Cientifica, (37), 197-214. https://www.redalyc.org/pdf/715/71543111012.pdf

Vago, T. M. (1999). Início e fim do século XX: maneiras de fazer educação física na escola. Cadernos Cedes, (48), 30-51. http://www.scielo.br/scielo.php?script=sci_arttext\&pid=S0101-32621999000100003\&lng=en\&nrm=iso

Vasconcellos, C. S. (2000). Planejamento: projeto de ensino-aprendizagem e projeto político pedagógico. São Paulo: Libertad. 